\title{
Types of Neurosurgical Patients Requiring Tracheostomy- Institution Based Study.
}

\author{
Jagat Narayan Rajbanshi ${ }^{1}$, Arbindra Kumar Yadav ${ }^{1}$, Dinesh Kumar Thapa ${ }^{1}$, Karuna \\ Tamrakar (Karki) ${ }^{1}$ \\ ${ }^{1} \mathrm{~B}$ and $\mathrm{C}$ Medical College Teaching Hospital and Research Center. \\ Correspondence: \\ Dr. Jagat Narayan Rajbanshi \\ Department of Neurosurgery, B \& C Medical College and Teaching Hospital \& Research \\ Center,Birtamode,Jhapa,Nepal. \\ Email: sergiorajbanshi@gmail.com \\ Phone: +9779818101187
}

\begin{abstract}
Background and purpose: Tracheostomy is common surgical procedure among neurosurgical patients who are ventilater dependent for prolonged period of time in neuro ICU. With the objective to analyzed various type of neurosurgical patients requiring tracheostomy this study was performed. Material and method: This is a Crossectional, Analytical stydt with Non probability consecutive sampling over the duration of 2 years. Association between age vs categories of different pathologies and Gender is categories of different neurological pathologies were analysed using Chi square test/fishers exact test wherever applicable using SPSS20. Result: There were total of 85 patients who underwent tracheostomy for various types of pathologies in our institute over the duration of two years. Mean age of patients who undergone tracheostomy was 45.26 ( SD 18.9) years and they ranged between 8 and 86 years. Among all these categories head injuries accounted for $45 \%$ of cases followed by ICH (28\%) Conclusion: Head Injury and intracerebral hemorrhage seems to be the common pathology requiring tracheostomy in tertiary neurosurgical centre. Young and male patients are more predominant in this study.
\end{abstract}

Key words: Neurosurgical ICU, Tracheostomy, head injury

$\mathrm{T}$ Tracheostomy is common surgical procedure among neurosurgical patients who are ventilator dependent for prolonged period of time in neuro ICU. ${ }^{1-4}$ There are various guideline weaning the patient off the ventilator in neurosurgical patient at the same time different centre have different common pathologies whom might be requiring tracheostomy in their institute. ${ }^{6,7}$ With the objective to analyzed various type of neurosurgical patients requiring tracheostomy this study was performed.

\section{Material and Methods}

Type of study: Crossectional, Analytical

Sampling Technique: Non probability consecutive sampling

Sample size: 85 patients

Duration: 2 years (Back dated from nov-2019)

Site of study: B\&C Medical College Teaching

Hospital and Research Center

\section{7}

Date submitted: 7/ 8/2019

Date accepted: 9/9/2019

\section{Data collection and analysis}

All the consecutive cases of tracheostomy done in neurological patients were collected over the study duration at our centre and data collection was done in preformed Proforma.

Quantitative data like age was presented as mean and standard deviation (S.D) \& qualitative data like Gender and categories of different neurological pathologies were presented as percentage. Association between age vs categories of different pathologies and Gender is categories of different neurological pathologies were analysed using Chi square test/ Fisher's exact test wherever applicable using SPSS20.

\section{Results}

There were total of 85 patients who underwent tracheostomy for various types of pathologies in our institute over the duration of two years. Mean

egneuro Volume 02, Issue 01, 2020 DOI:https://doi.org10.3126/egn.v2i1.27458 
age of patients who undergone tracheostomy was 45.26 (SD 18.9) years and they ranged between 8 and 86 years. There was male predominance who accounted around 79\% (Figure 1). The different categories of diseases that needed tracheostomy were Head injuries, intracerebral hemorrhages, spinal injuries, malignant middle cerebral infarction and others. Patients categorized in "others" included cases like encephalitis, hydrocephalus, aneurysms, tetanus, tumors, and post CPR hypoxic brain injuries. Among all these categories head injuries accounted for $45 \%$ of cases followed by ICH (28\%) (Figure 2).

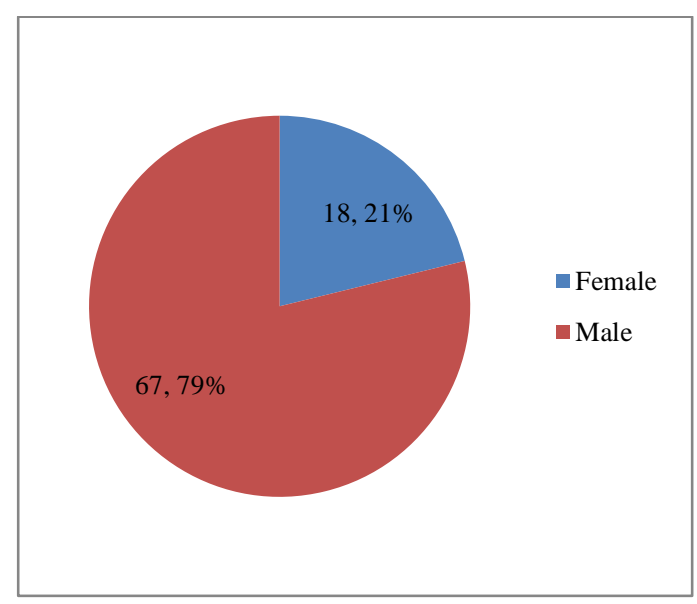

Figure 1: Distribution of Gender

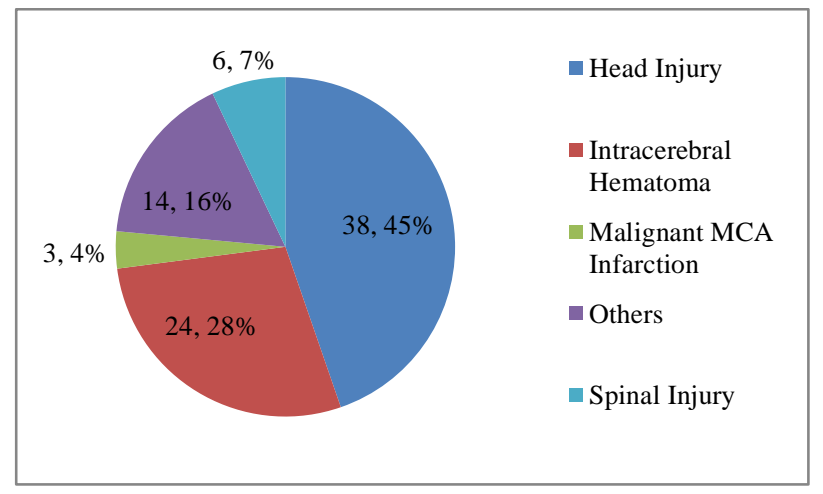

Figure 2: Distribution of Diseases

There was no significant association between age and different categories of pathologies which was analysed using Chi Square test (Table 1). Similarly, gender when analyzed with different categories of diseases showed no significant findings (Table 2).

\section{Discussion}

The mean age of the patients who required tracheostomy in neurosurgical ICU was 45.26 (S.D 18.9) years. This younger age might be due to high prevalence of severely Head Injured young patients $(45 \%)$ in this study. The incidence of Head Injury is common in young patients throughout the world; and so the tracheostomy or other supportive surgical procedure. ${ }^{8-10}$

This study showed higher prevalence of the male patients requiring tracheostomy. The higher percentage of the male Gender might be due to high involvement of them in motor vehicle accident in Nepal.11-13 In different neurosurgical centre the pattern of neurosurgical patients differ like tertiary care centre they might have higher prevalence of neurooncological cases but in our part of the world most of the neurosurgical centre have trauma related patients. This seems to be true in our institute as well, As in this study the tracheostomy prevalence is higher in Head Injury $(45 \%)$ followed by Intracerebral hemorrhage $(28 \%)$.

Although the mean age was 45.26(S.D 18.9) year and male predominance $(79 \%)$ in this study there was no significant association with different categories of pathologies who underwent tracheostomy; hence no added risk seems to be involved.

\section{Conclusion}

Head Injury and intracerebral hemorrhage seems to be the common pathology requiring tracheostomy in tertiary neurosurgical centre. Young and male patients are more predominant in this study 
Table 1: Association of age with different categories of diseases.

\begin{tabular}{|c|c|c|c|c|c|c|c|}
\hline $\begin{array}{l}\text { Age } \\
\text { category }\end{array}$ & $\begin{array}{l}\text { Head } \\
\text { Injury }\end{array}$ & $\begin{array}{l}\text { Intracerebral } \\
\text { Hematoma }\end{array}$ & $\begin{array}{l}\text { Malignant } \\
\text { MCA } \\
\text { Infarction }\end{array}$ & Others & $\begin{array}{l}\text { Spinal } \\
\text { Injury }\end{array}$ & & P Value \\
\hline$<10$ & 1 & 0 & 0 & 1 & 0 & 2 & \\
\hline $10-19$ & 3 & 0 & 0 & 0 & 0 & 3 & \\
\hline $20-29$ & 12 & 0 & 0 & 3 & 1 & 16 & \\
\hline $30-39$ & 9 & 0 & 1 & 1 & 1 & 12 & \\
\hline $40-49$ & 5 & 7 & 1 & 1 & 2 & 16 & 0.09 \\
\hline $50-59$ & 4 & 4 & 1 & 3 & 1 & 13 & \\
\hline $60-69$ & 2 & 7 & 0 & 4 & 1 & 14 & \\
\hline $70-79$ & 2 & 4 & 0 & 0 & 0 & 6 & \\
\hline $80-89$ & 0 & 2 & 0 & 1 & 0 & 3 & \\
\hline Total & 38 & 24 & 3 & 14 & 6 & 85 & \\
\hline
\end{tabular}

Table 2: Association of gender with different categories of diseases.

\begin{tabular}{llllllll}
\hline Gender & $\begin{array}{l}\text { Head } \\
\text { Injury }\end{array}$ & $\begin{array}{l}\text { Intracerebral } \\
\text { Hematoma }\end{array}$ & $\begin{array}{l}\text { Malignant } \\
\text { MCA } \\
\text { Infarction }\end{array}$ & Others & $\begin{array}{l}\text { Spinal } \\
\text { Injury }\end{array}$ & Total & P Value \\
\hline Female & 5 & 9 & 0 & 4 & 0 & 18 & 0.1 \\
Male & 33 & 15 & 3 & 10 & 6 & 67 & 85 \\
\hline Total & 38 & 24 & 3 & 14 & 6 & \\
\hline
\end{tabular}

\section{References}

1. Teoh WH, Goh KY, Chan C. The role of early tracheostomy in critically ill neurosurgical patients. ANNALS-ACADEMY OF MEDICINE SINGAPORE. 2001 May 1;30(3):234-8.

2. Miller JD, Kapp JP. Complications of tracheostomies in neurosurgical patients. Surgical neurology. 1984 Aug 1;22(2):186-8.

3. Boyd SW, Benzel EC. The role of early tracheotomy in the management of the neurosurgical patient. The Laryngoscope. 1992 May;102(5):559-62.

4. Koh WY, Lew TW, Chin NM, Wong MF. Tracheostomy in a neuro-intensive care setting: indications and timing. Anaesthesia and intensive care. 1997 Aug;25(4):365-8.

5. Dunham CM, Cutrona AF, Gruber BS, Calderon JE, Ransom KJ, Flowers LL. Early tracheostomy in severe traumatic brain injury: evidence for decreased mechanical ventilation and increased hospital mortality. International journal of burns and trauma. 2014;4(1):14.

6. Harrop JS, Sharan AD, Scheid EH, Vaccaro AR, Przybylski GJ. Tracheostomy placement in patients with complete cervical spinal cord injuries: American Spinal Injury Association Grade A. Journal of Neurosurgery: Spine. 2004 Jan 1;100(1):20-3.

7. Munakomi S, Tamrakar K. Introducing'AZ'algorithm for extubation. International Journal of Students' Research. 2014 Jul 1;4(2):56.
8. Overgaard J, Hvid-Hansen O, Land AM, Pedersen $\mathrm{K}$, Christensen S, Haase J, Hein O, Tweed W. Prognosis after head injury based on early clinical examination. The Lancet. 1973 Sep 22;302(7830):631-5.

9. Al-Kandary N, Al-Waheeb S. Patterns of accidental deaths in Kuwait: a retrospective descriptive study from 2003-2009. BMC public health. 2015 Dec;15(1):302.

10. Sharifah Allyana SM, Zarir HZ, Abdul Rahmat AM, Siti Atiqah MF, Noor FP, Wong SV, Jamilah MJ. Recent trend of fatal motorcycle crashes in Malaysia. InProceedings of the 8th International Forum of Automotive Traffic Safety (INFATS) 2010 Dec.

11. Agrawal A, Agrawal CS, Kumar A, Lewis O, Malla G, Khatiwada R, Rokaya P. Epidemiology and management of paediatric head injury in eastern Nepal. African journal of paediatric surgery. 2008 Jan 1;5(1):15.

12. Mishra B, Sinha ND, Sukhla SK, Sinha AK. Epidemiological study of road traffic accident cases from Western Nepal. Indian journal of community medicine: official publication of Indian Association of Preventive \& Social Medicine. 2010 Jan;35(1):115.

13. Munakomi S. A comparative study between Marshall and Rotterdam CT scores in predicting early deaths in patients with traumatic brain injury in a major tertiary care hospital in Nepal. Chinese Journal of Traumatology. 2016 Feb 1;19(1):25-7. 